\title{
PARÂMETROS FISIOLÓGICOS E DESEMPENHO DE OVINOS SANTA INÊS SUBMETIDOS A DIFERENTES TIPOS DE SOMBREAMENTO E A SUPLEMENTAÇÃO EM PASTEJO ${ }^{1}$
}

\author{
Physiologic behavior and performance of lambs Santa Inês breed submitted to different \\ types of environmental and supplementation in grazing
}

\author{
Iremar Silva Andrade², Bonifácio Benício de Souza ${ }^{3}$, José Morais Pereira Filho ${ }^{3}$, Aderbal Marcos de Azevedo Silva ${ }^{3}$
}

\section{RESUMO}

Objetivou-se com este trabalho avaliar o efeito da disponibilidade de sombra e da suplementação com concentrado sobre o comportamento fisiológico e o desempenho de cordeiros Santa Inês em pastejo no semi-árido paraibano. Foram utilizados 27 ovinos machos da raça Santa Inês, com peso vivo médio de 21,5 kg e 120 dias idade. Os animais foram distribuídos aleatoriamente em três ambientes [sem sombra (SS), sombra natural (SN) e sombra artificial (SA)] e alimentados com três níveis de suplementação concentrada $(0,1,0$ e $1,5 \% \mathrm{PV})$. A análise de variância revelou efeito significativo do turno da tarde em relação ao da manhã sobre a temperatura retal (TR). Contudo, não se verificou efeito significativo dos fatores ambiente e dieta sobre a TR. A frequiência respiratória foi maior no turno tarde do que no da manhã nos ambientes de SS (35,28 e 61,64 mov/mim) e SA (30,28 e 51,76 mov/mim). A dieta influenciou a ingestão de matéria seca (IMS) no ambiente SS. A temperatura superficial foi mais elevada no turno da tarde do que pela manhã, independente dos fatores estudados. Os animais que receberam suplementação apresentaram um melhor desempenho em relação aos não suplementados. Concluiu-se com esta pesquisa que o uso de sombreamento nas pastagens melhora os índices de conforto térmico do ambiente, e que o desempenho de cordeiros da raça Santa Inês, em pastagem nativa enriquecida com capim buffel pode ser melhorado com a utilização de concentrado.

Termos para indexação: Ambiente, conversão alimentar, dieta, freqüência respiratória, temperatura retal.

\begin{abstract}
The objective of this work was to evaluate the effect of the shadow and food supplementation on the physiologic behavior and performance of Santa Inês lambs under rangeland conditions in the semi-arid region of Paraíba. Twenty-seven male lambs were used, with an average body weight of $21.5 \mathrm{~kg}$ and 120 days of age. They were randomly distributed in three environments [without shade (WS), natural shade (NS) and artificial shade (AS)] and fed growing three levels of concentrate supplement $(0,1.0$ and $1.5 \%$ of live body weight). The analysis of variance revealed significant effect of period (morning $\mathrm{x}$ afternoon) on rectal temperature. However, no significant effect was observed for the environment and diet factors. Breathing frequency was higher in the afternoon than in the morning in the WS (35.28 and $61.64 \mathrm{mov} /$ minute) and AS (30.28 and $51.76 \mathrm{mov} /$ minute) environments. The diet influenced DM ingestion in SS environment. Skin temperature was higher in afternoon than in the morning, independent of the studied factors. The animals supplemented with concentrate mixtures had a performance better than the control ones. It was concluded that shading improved the indexes of thermal comfort and animal physiology and production parameters. Santa Inês breed showed high adaptability to the adverse conditions of the semi- arid region of Paraíba. The performance of Santa Inês lambs under a buffel enriched native rangeland, can be improved by supplementation with concentrate.
\end{abstract}

Index terms: Environment, feed conversion, breathing frequency, rectal temperature.

(Recebido em 22 de novembro de 2005 e aprovado em 11 de outubro de 2006)

\section{INTRODUÇÃO}

O Semi-Árido brasileiro ocupa $86 \%$ da região Nordeste e caracteriza-se por apresentar um período chuvoso, no qual as pastagens são abundantes e de boa qualidade nutritiva, todavia, na época da seca ocorre uma redução na capacidade de suporte das mesmas, em virtude da redução na disponibilidade e qualidade da forragem, decorrente de sua lignificação (ARAÚJO FILHO et al., 1998). Mesmo com as adversidades climáticas, o rebanho ovino do Nordeste é de 8.060.619 milhões de cabeças correspondendo a 55\% do rebanho nacional (IBGE, 2001), no entanto apesar deste efetivo os índices de produtividade são considerados baixos.

Acredita-se que a utilização de técnicas de manejo para amenizar os efeitos do clima e melhorar a utilização das forragens através da suplementação com concentrado é possível obter efeito aditivo no aproveitamento dos nutrientes e elevar o nível de produtividade dos ovinos no

'Parte da dissertação de Mestrado do primeiro autor apresentada ao PPGZ - universidade Federal de Campina Grande - 58.700-000 - Patos, PB Pesquisa financiada pela CAPES/CNPQ/UFCG.

${ }^{2}$ Mestrando em Zootecnia do CSTR - Universidade Federal de Campina Grande/UFCG - Centro de Saúde e Tecnologia Rodovia Patos/CSTR Teixeira Km 0 - Jatobá - Cx. P. 64 - 58.700-970 - Patos, PB - iremarandrade@hotmail.com

${ }^{3}$ Professor do Departamento de medicina Veterinária/DMV - Universidade Federal de Campina Grande/UFCG - Campus de Patos - Patos, PB. 
semi-árido. Embora haja um número considerável de trabalhos sobre ambiência, conforto térmico e desempenho de ovinos, são escassos os estudos que associem o efeito do sombreamento e da suplementação concentrada sobre os parâmetros fisiológicos e produtivos de ovinos em pastejo.

Pádua \& Silva (1996) relatam que ao se optar pela criação de determinada raça ovina, para produção nos trópicos, deve-se levar em conta sua adaptação a este ambiente e os efeitos deste sobre as características fisiológicas e de desempenho dos animais. Segundo Baccari Júnior (1990), as avaliações de adaptabilidade dos animais aos ambientes quentes podem ser realizadas por meio de testes de adaptabilidade fisiológica ou de rendimento. Os critérios de tolerância e adaptação dos animais são determinados por medidas fisiológicas, tais como temperatura corporal, frequência respiratória e batimento cardíaco (ABI SAAB \& SLEIMAN, 1995).

O aumento da temperatura da pele, elevação da temperatura retal, aumento da freqüência respiratória, diminuição da ingestão de alimentos e redução do nível de produção são para Lu (1989), indicadores diretos do estresse calórico. Bianca \& Kunz (1978) preconizam que a temperatura retal (TR) e freqüência Respiratória (FR) são consideradas as melhores referências fisiológicas para estimar a tolerância dos animais ao calor.

De acordo com Targa et al. (1993), as modificações no ambiente natural parecem ser essenciais para elevar o desempenho produtivo dos animais em regiões de clima quente. A manutenção de ovinos em crescimento em condições de pastejo deve prever a suplementação alimentar com concentrados (BARBOSA et al., 2003). O desempenho de cordeiros em pastejo pode ser melhorado com o fornecimento de suplementação concentrada (SOUZA et al., 2005).

De acordo com Neiva et al. (2004), o tipo de dieta influencia de forma significativa a susceptibilidade dos animais aos efeitos ambientais mesmo no caso de animais deslanados de raças originarias de regiões tropicais, como a Santa Inês. Desta forma, as interações entre tipo de alimento, consumo, ambiente e parâmetros fisiológicos devem ser avaliadas, visando melhorar o desempenho dos animais em regiões quentes. Objetivou-se com este trabalho avaliar o efeito do sombreamento e da suplementação com concentrado sobre o comportamento fisiológico e desempenho de ovinos Santa Inês em pastejo no semi-árido paraibano.

\section{MATERIAL E MÉTODOS}

O experimento foi desenvolvido no Centro de Saúde e Tecnologia Rural da Universidade Feral de
Campina Grande, Campus de Patos, $\mathrm{PB}$, na região semiárida.

A região caracteriza-se por apresentar um clima $\mathrm{BSH}$ (Köppen) classificado como quente e seco, com temperatura máxima de $32,9{ }^{\circ} \mathrm{C}$ e mínima de $20,8{ }^{\circ} \mathrm{C}$ e umidade relativa de $61 \%$ (BRASIL, 1992).

Foram utilizados 27 ovinos machos da raça Santa Inês, com peso vivo médio de $21,5 \mathrm{~kg}$ e 120 dias idade, distribuídos em três ambientes: sem sombra (SS), sombra natural (SN), proveniente de um cajueiro sombra artificial (SA), constituída por uma tela de polietileno com $80 \%$ de retenção (sombrite), e níveis crescentes de suplementação concentrada ( $0,1,0$ e $1,5 \%$ do peso vivo "PV").

Os animais tiveram acesso diariamente à pastagem nativa enriquecida com capim buffel (Cenchrus ciliaris $\mathrm{L}$ CV. Bioela), das 7:00 às 16:00 horas, quando eram recolhidos e mantidos durante a noite em baias coletivas (uma para cada nível de suplementação) com $1,0 \mathrm{~m}^{2} /$ animal equipadas com comedouros e bebedouros, onde recebiam a suplementação nos níveis de $0,1,0$ e $1,5 \%$ do peso vivo.

As dietas experimentais constituiram-se em pastagem nativa e água "ad libitum" e suplementação concentrada nos níveis de $0,1,01,5 \%$ do peso vivo (\%PV), ajustada a partir de farelo de milho $(40,4 \%)$, farelo de soja $(56,6 \%)$ e mistura mineral $(3,0 \%)$, de modo que a última dieta $(1,5 \% \mathrm{PV})$ viesse a atender às recomendações de proteína bruta (PB) e energia metabolizável (EM), preconizadas pelo AFRC (1993), para um ganho de peso médio diário de $200 \mathrm{~g} / \mathrm{dia}$. Os dados referentes à composição química do concentrado, e da disponibilidade da forragem, estão apresentados na Tabela 1.

As variáveis ambientais registradas foram a temperatura do Globo Negro (TGN), por intermédio do termômetro de globo negro de Vernon e a temperatura seca (TBS) e úmida (TBU), pelo termômetro de bulbo seco e bulbo úmido, a temperatura máxima (TMAX) e mínima (TMIN), através de termômetros de máxima e mínima. O ITGU (Índice de Temperatura do Globo Negro e Umidade) foi determinado conforme metodologia de Buffington et al. (1981).

As leituras foram realizadas às 9:00 e às 15:00 horas, em todos os ambientes experimentais, obedecendo às normas meteorológicas internacionais. Os parâmetros fisiológicos avaliados foram: Temperatura retal (TR), Frequiência respiratória (FR), e Temperatura superficial (TS). Mensurados e registrados durante todo período experimental, nos turnos manhã (8:30h às 9:30h) e da tarde (14:30h às 15:30h). A TR foi mensurada com termômetro clínico veterinário e a FR através de estetoscópio 
veterinário, auscultando-se por 15 segundos e o resultado multiplicado por quatro, obtendo-se assim a freqüência em um minuto. A TS obtida por meio de termômetro infravermelho digital em oito pontos determinados do corpo do animal: fronte, dorso, garupa, lombo, costado, flanco, coxa e ventre.

O ganho de peso médio diário GPMD (g/dia), conversão alimentar (CA), foram obtidos através de pesagens realizadas a cada 21 dias. A ingestão de matéria seca de (IMS), em cada ambiente estudado em função do nível de suplementação utilizado, foi obtido através de um levantamento inicial e final da disponibilidade de forragem, por intermédio de um quadro medindo 1,00 m x $0,25 \mathrm{~m}$, para demarcar a área vegetal no solo a ser coletada.

As amostras da forragem foram submetidas a um ensaio de digestibilidade in situ e in vitro, com o propósito de utilizar estas variáveis como ferramenta na determinação do consumo de forragem. Foi utilizado como indicador de digestibilidade e consumo, o Hidroxifenilpropano modificado e enriquecido (LIPE), o qual foi administrado diariamente uma cápsula de $250 \mathrm{mg}$ diretamente no esôfago do animal através de uma sonda esofágica em cada cordeiro, durante um período de 5 dias, as amostras de fezes foram coletadas diretamente no reto do animal a partir do segundo dia de administração obtendo-se no final uma amostra composta para cada animal.

O delineamento experimental para parâmetros fisiológicos foi o inteiramente casualizado num esquema fatorial de $3 \times 3 \times 2$, três ambientes (SS, SN, e SA) e três níveis de suplementação $(0,1,0$, e $1,5 \%$ do PV) e dois turnos (manhã e tarde), tendo sido utilizados os mesmos animais (em ambos os turnos), com 3 repetições. Para os parâmetros de desempenho utilizou-se um delineamento inteiramente casualizado em fatorial $3 \times 3$, três ambientes
(SS, SN, e SA) e três níveis de suplementação $(0 ; 1,0$; e $1,5 \%$ do PV), com 3 repetições.

Os dados obtidos foram submetidos à análise de variância pelo programa SAS Institute (1999) e os valores médios comparados pelo teste de Tukey a $5 \%$ de probabilidade.

\section{RESULTADOS E DISCUSSÃO}

\section{Variáveis ambientais}

As médias da temperatura máxima e mínima durante o período experimental foram de $35,17^{\circ} \mathrm{C}$ e $20,67{ }^{\circ} \mathrm{C}$ e de $37,00{ }^{\circ} \mathrm{C}$ e $21,92{ }^{\circ} \mathrm{C}$, para os ambientes de SN e SA respectivamente. As médias referentes às demais variáveis ambientais estudadas encontram-se na Tabela 2.

A análise de variância revelou efeito significativo $(\mathrm{P}<0,05)$ do ambiente e do turno para as variáveis avaliadas, contudo não foi verificada interação significativa entre os fatores ( $p>0,05)$. A TBS foi mais elevada no ambiente de SA $(p<0,05)$ em relação a SN. Não houve diferença significativa $(p>0,05)$ para UR entre os ambientes SN e SA.

O ITGU observado nos três ambientes SS, SN e SA e nos turnos manhã apresentaram-se elevados. Dentre os fatores estudados o turno foi o mais importante sobre as respostas fisiológicas dos animais, sendo o turno da tarde o que causa mais desconforto térmico aos animais em relação ao da manhã, fato este observado através do aumento da TR e FR.

\section{Respostas fisiológicas}

As médias referentes à temperatura retal (TR) encontram-se na (Figura 1), onde a análise de variância revelou efeito significativo $(\mathrm{p}<0,05)$ do turno da tarde em relação ao da manhã sobre a TR, contudo não se verificou efeito significativo $(p>0,05)$ dos fatores ambiente e dieta

TABELA 1 - Composição química dos ingredientes utilizados no ajuste das dietas experimentais.

\begin{tabular}{lcccccc}
\hline Ingredientes & MS (\%) & EB $^{\mathbf{1}}(\mathbf{K c a l} / \mathbf{k g})$ & PB $(\boldsymbol{\%})$ & FDN & FDA & Cinzas $(\%)$ \\
\hline Farelo de soja & 91,64 & 5310 & 45,96 & 7,90 & 3,82 & 7,27 \\
Farelo de milho & 90,02 & 5670 & 9,73 & 9,00 & 4,01 & 6,02 \\
Gramínea in & 66,54 & 4479 & 4,08 & 79,27 & 49,32 & 7,30 \\
Gramínea fn & 66,35 & 4493 & 2,80 & 80,79 & 52,71 & 7,66 \\
Leguminosa in & 50,63 & 4418 & 9,22 & 68,31 & 45,75 & 6,70 \\
Leguminosa fn & 68,54 & 4633 & 3,76 & 77,47 & 54,50 & 3,64 \\
1=Kcal/kg & & & & & & \\
- in (início do experimento) & & & & & &
\end{tabular}

Ciênc. agrotec., Lavras, v. 31, n. 2, p. 540-547, mar./abr., 2007 
sobre esta variável. Resultados estes superiores aos obtidos por Cezário et al. (2004). Todavia assemelha-se aos resultados obtidos por Arruda et al. (1998) em estudo com ovinos da raça Santa Inês em condições de semiárido.

Não foi verificado efeito significativo $(\mathrm{p}>0,05)$ da dieta $(0,1,0$ e $1,5 \% \mathrm{PV})$ sobre a TR. Resultados contrários aos de Neiva et al. (2004) em ovinos da mesma raça alimentados com dietas contendo alto teor de concentrado.
O turno influenciou de forma significativa $(\mathrm{p}<0,05)$ a TR dos animais, sendo observada a maior média no turno da tarde em relação ao da manhã, resultados que se assemelham aos de (CESAR et al., 2004; NEIVA et al., 2004).

Para a FR verificou-se interação significativa $(\mathrm{P}<0,05)$ entre os fatores, turno e ambiente. As médias da FR em função do turno e do ambiente encontram-se na Tabela 3.

TABELA 2 - Médias das variáveis ambientais, temperatura do bulbo seco (TBS), umidade relativa do ar (UR), temperatura do globo negro (TGN) e do índice de temperatura do globo negro e umidade (ITGU) em função do ambiente (sem sombra, sombra natural e sombra artificial) e dos turnos manhã e tarde.

\begin{tabular}{|c|c|c|c|c|}
\hline \multirow[b]{2}{*}{ Ambiente } & \multicolumn{4}{|c|}{ Variáveis ambientais } \\
\hline & TBS $\left({ }^{\circ} \mathbf{C}\right)$ & UR (\%) & TGN $\left({ }^{\circ} \mathbf{C}\right)$ & ITGU \\
\hline Sem sombra & ---------------- & --------------. & $43,83 \mathrm{~A}$ & $91,28 \mathrm{~A}$ \\
\hline Sombra natural & 31,91B & $40,58^{\mathrm{A}}$ & $36,16 \mathrm{~B}$ & $83,61 \mathrm{~B}$ \\
\hline Sombra artificial & $34,94^{\mathrm{A}}$ & $41,75^{\mathrm{A}}$ & $36,66 \mathrm{~B}$ & $85,11 \mathrm{~B}$ \\
\hline Turno & & & & \\
\hline Manhã & $30,66 \mathrm{~B}$ & $45,72^{\mathrm{A}}$ & $37,10 \mathrm{~B}$ & $85,10 \mathrm{~B}$ \\
\hline Tarde & $34,75^{\mathrm{A}}$ & $36,22 \mathrm{~B}$ & $40,44 \mathrm{~A}$ & $88,24 \mathrm{~A}$ \\
\hline CV $(\%)$ & 5,9303 & 14,090 & 7,3134 & 3,8171 \\
\hline
\end{tabular}

Médias seguidas por letras maiúsculas diferentes na coluna para cada fator são estatisticamente diferentes pelo teste de Tukey a $(5 \%)$.

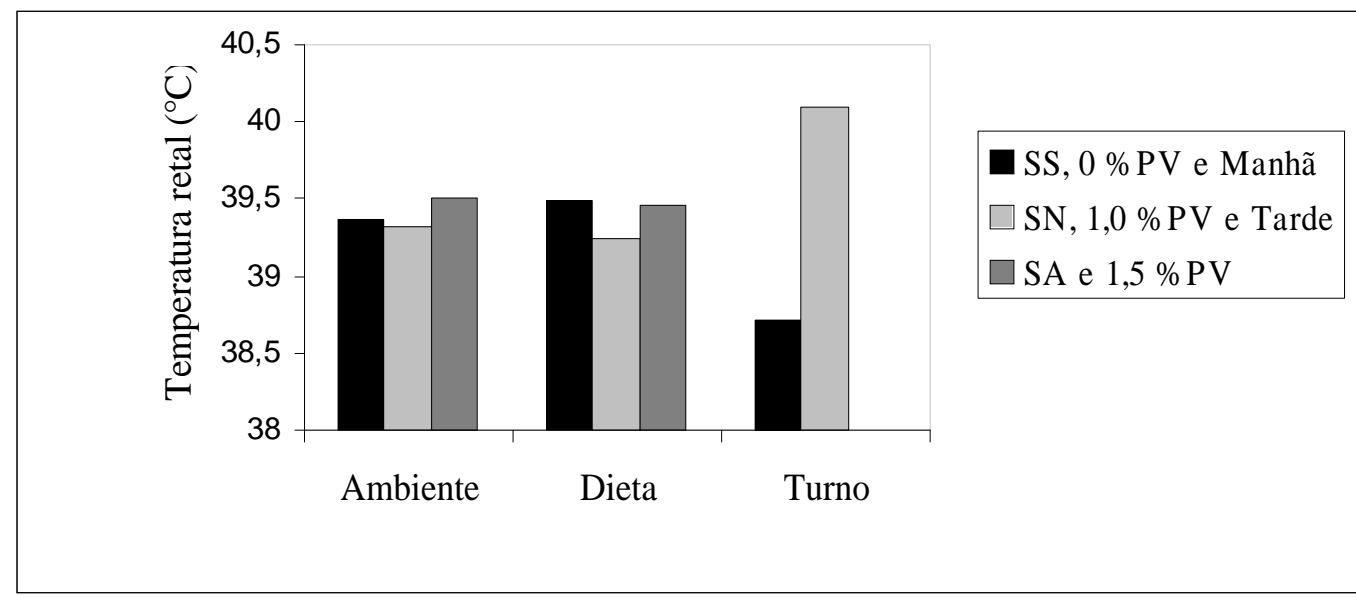

FIGURA 1 - Médias da temperatura retal $\left(\mathrm{TR}^{\circ} \mathrm{C}\right)$ em função do ambiente (sem sombra, sombra natural e sombra artificial) da dieta (0, 1,0 e 1,5\%PV) e dos turnos manhã e tarde. 
TABELA 3 - Médias da freqüência respiratória (FR), em função do ambiente e do turno.

\begin{tabular}{lcc}
\hline \multicolumn{3}{c}{ FR (mov/mim) } \\
\hline Ambiente & \multicolumn{2}{c}{ Turno } \\
Sem sombra & $35,28 \mathrm{Ba}$ & Tarde \\
Sombra natural & $30,00 \mathrm{Aa}$ & $35,64 \mathrm{Aa}$ \\
Sombra artificial & $30,28 \mathrm{Ba}$ & $51,76 \mathrm{Ab}$ \\
\hline CV $(\%)$ & & 17,48 \\
\hline
\end{tabular}

Médias seguidas de letras diferentes maiúsculas na linha e minúsculas na coluna são estatisticamente diferentes pelo teste de Tukey (5\%).

Observa-se que a FR foi significativamente maior $(\mathrm{P}<0,05)$ durante o turno da tarde em comparação ao da manhã nos ambientes de SS e SA, contudo não apresentou diferença significativa para os animais do ambiente de SN. Com relação a ambiente dentro de turnos não houve diferença significativa $(\mathrm{P}>0,05)$ entre os ambientes estudados no turno da manhã, no entanto à tarde foi observada diferença significativa $(\mathrm{P}<0,05)$, em todos os ambientes estudados. Sendo a maior média observada $(\mathrm{P}<0,05)$ no ambiente de SS $(61,64 \mathrm{mov} / \mathrm{mim})$ e a menor no $\mathrm{SN}(35,59 \mathrm{mov} / \mathrm{mim})$.

Deve-se considerar a importância do sombreamento natural nas pastagens, pois promove o conforto térmico dos animais, como observado nesta pesquisa através da $\mathrm{FR}$, que foi inferior $(\mathrm{P}<0,05)$ às observadas nos ambientes SS e SA, o que está confirmado através do ITGU $(83,62)$ observado, em relação aos demais ambientes estudados $(85,12$ e 91,28$)$ para a SA e SS. Para Silanikove (2000), a taxa de respiração pode quantificar a severidade do estresse pelo calor, em uma freqüência de 40-60, 60-80 e 80-120 mov/ mim caracteriza um estresse baixo, médio-alto e alto para ruminantes, podendo-se dizer que os ovinos não sofreram estresse pela manhã em nenhum dos ambientes estudados, e no período da tarde os animais do ambiente SS apresentaram uma situação de estresse térmico médio-auto, diferenciando dos demais SN e SA que foram considerados como estresse baixo.

Segundo Mendes et al. (1976), em ovinos a frequiência respiratória pode atingir até $400 \mathrm{mov} / \mathrm{mim}$. Terrill \& Slee (1991) verificaram em ovinos estressados FR de 300 mov/mim, valor bem superior aos encontrados neste trabalho que não ultrapassaram $61,64 \mathrm{mov} / \mathrm{mim}$ no ambiente SS considerado mais desconfortável (ITGU=91,28).
As médias referentes à temperatura superficial (TS), em função dos fatores, turno, ambiente e dieta encontram-se na Tabela 4. A análise de variância revelou interação significativa $(\mathrm{P}<0,05)$ entre os fatores para a TS.

A TS foi mais elevada $(\mathrm{P}<0,05)$ no turno da tarde em comparação ao da manhã, independente dos fatores estudados. O ambiente apresentou efeito significativo $(\mathrm{P}<0,05)$ apenas no turno da tarde, tendo o ambiente SS apresentado a maior média e o de $\mathrm{SN}$ a menor, o que possivelmente pode ser explicado devido a menor incidência de radiação solar na $\mathrm{SN}$, onde os animais sofreram menor aquecimento corporal.

TABELA 4 - Médias da temperatura superficial (TS), em função do ambiente e da dieta, em dois turnos estudados (manhã e tarde).

\begin{tabular}{lcc}
\hline & \multicolumn{2}{c}{ TS $\left(\mathbf{C}^{\circ}\right)$} \\
\hline Ambiente & Manhã & Tarde \\
Sem sombra & $31,69 \mathrm{Ba}$ & $38,55 \mathrm{Aa}$ \\
Sombra natural & $31,39 \mathrm{Ba}$ & $32,17 \mathrm{Ac}$ \\
Sombra & $31,88 \mathrm{Ba}$ & $33,71 \mathrm{Ab}$ \\
artificial & & \\
\hline Dieta & & $34,06 \mathrm{Ab}$ \\
$0 \%$ & $31,97 \mathrm{Ba}$ & $35,41 \mathrm{Aa}$ \\
$1,0 \%$ & $31,65 \mathrm{Ba}$ & $34,97 \mathrm{Aa}$ \\
\hline CV $(\%)$ & $31,34 \mathrm{Ba}$ & \\
\hline
\end{tabular}

Médias seguidas de letras diferentes maiúsculas na linha e minúsculas na coluna são estatisticamente diferentes pelo teste de Tukey (5\%).

A ingestão de matéria seca (IMS) em função do ambiente e das dietas fornecidas encontram-se na Tabela 5.

A análise de variância revelou interação $(\mathrm{p}<0,05)$ dos fatores ambiente e dieta para ingestão de matéria seca (IMS). Para os animais não suplementados ( $0 \% \mathrm{PV})$, observa-se que a maior média $(\mathrm{p}<0,05)$ foi obtida no ambiente de SS (583 g/dia), não havendo diferença significativa ( $p>0,05)$ entre os ambientes de SN e SA (494 e $498 \mathrm{~g} /$ dia, respectivamente). Para os animais que receberam 1,0 e 1,5\%PV de suplementação, não se verificou efeito significativo ( $p>0,05)$ dos ambientes de SS, SN e SA.

Deve-se considerar o efeito do ambiente sobre a IMS dos animais não suplementados, onde mesmo em condições desfavoráveis (ITGU $=91,28$ no SS), os animais apresentaram maior consumo que os mantidos em 
TABELA 5 - Médias da ingestão de matéria seca (IMS) em função do ambiente (sem sombra, sombra natural e sombra artificial) e da dieta (0, 1,0 e 1,5\%PV).

\begin{tabular}{lccc}
\hline \multicolumn{4}{c}{ Ingestão de matéria seca (g/dia) } \\
\hline \multicolumn{4}{c}{ Ambiente } \\
\hline Dieta & SS & SN & SA \\
\hline $0 \% \mathrm{PV}$ & $583 \mathrm{Ab}$ & $494 \mathrm{Bc}$ & $498 \mathrm{Bc}$ \\
$1,0 \% \mathrm{PV}$ & $617 \mathrm{Ab}$ & $655 \mathrm{Ab}$ & $609 \mathrm{Ab}$ \\
$1,5 \% \mathrm{PV}$ & $719 \mathrm{Aa}$ & $771 \mathrm{Aa}$ & $747 \mathrm{Aa}$ \\
\hline $\mathrm{CV}(\%)$ & 4,9930 & & \\
\hline
\end{tabular}

Médias seguidas por letras diferentes maiúsculas na linha e minúscula na coluna são estatisticamente diferentes pelo teste de Tukey a $5(\%)$.

ambientes sombreados SN e SA. Resultados que são contraditórios aos observados na literatura internacional (HAFEZ, 1973), que relata que à medida que a temperatura do meio se eleva, ocorre uma redução na ingestão de alimentos, contudo este resultado pode ser atribuído ao fato dos animais suplementados terem sombra à disposição e passarem menos tempo pastejando e assim suas exigências atendidas num período de tempo menor do que os animais do mesmo ambiente que não receberam suplementação.

Avaliando-se dietas dentro de ambientes, observase que houve efeito significativo $(\mathrm{p}<0,05)$ da dieta em todos os ambientes estudados, sendo as maiores médias obtidas para o tratamento com $1,5 \% \mathrm{PV}$. No ambiente SS, considerado o mais desconfortável os animais não suplementados apresentaram uma IMS dentro do esperado, contudo à medida em que receberam os níveis de 1,0 e $1,5 \%$ PV de suplementação aumentaram este consumo, repercutindo assim no desempenho dos animais, onde independentemente do nível de suplementação observado estes mantiveram um ganho de peso médio diário dentro do esperado, o que demonstra que mesmo em ambientes hostis o Santa Inês consegue manter uma ótima eficiência de produção com ganhos diário satisfatórios, demonstrado assim grande adaptabilidade às condições do semi-árido.

Neiva et al. (2004) observaram que ovinos Santa Inês mantidos a sombra apresentaram uma maior ingestão de matéria seca (1062 $\mathrm{g} /$ dia) em relação àqueles mantidos ao sol (944 g/dia), os resultados encontrados neste trabalho são inferiores a estes, contudo superam os encontrados por Arruda et al. (1998) que obtiveram para ovinos Santa
Inês alimentados com dieta abaixo da mantença consumo de matéria seca de $331 \mathrm{~g} /$ dia ao sol e de $326 \mathrm{~g} /$ dia à sombra.

As médias referentes ao ganho de peso médio diário (GPMD) e a conversão alimentar (CA) encontram-se na (Figuras 2 e 3). A análise de variância revelou efeito significativo $(p<0,05)$ da dieta sobre o GPMD e CA. Contudo, não foi verificado efeito do ambiente $(p>0,05)$ sobre estes parâmetros. Estes resultados superam os obtidos por Arruda et al. (1998) que encontraram ganhos de 130 e $145 \mathrm{~g} /$ dia para animais mantidos ao sol e a sombra respectivamente, e recebendo alto nível de concentrado.

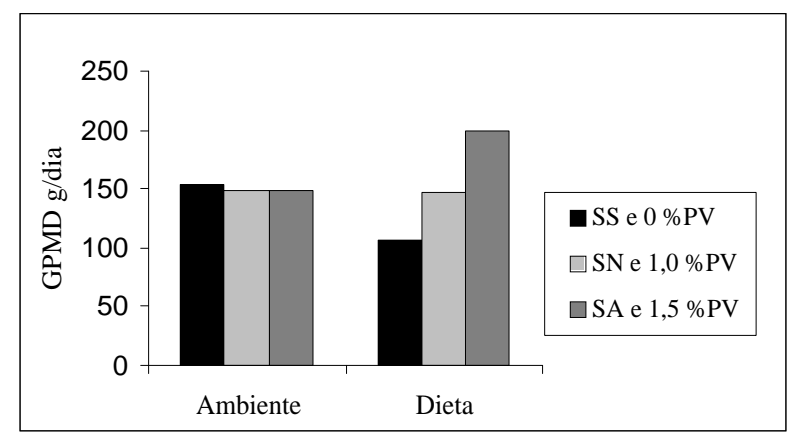

FIGURA 2 - Médias do ganho de peso médio diário (GPMD $\mathrm{g} /$ dia) em função do ambiente (sem sombra, sombra natural e sombra artificial) e da dieta (0, 1,0 e 1,5\%PV).

Para a dieta verifica-se que houve diferença significativa $(p<0,05)$ entre os níveis de suplementação utilizados, sendo a menor média obtida pelos animais não suplementados e a maior para os animais que receberam $1,5 \% \mathrm{PV}$ como suplemento.

Estes resultados superam os obtidos por Neiva et al. (2004) que obtiveram ganhos de $82 \mathrm{~g} /$ dia para ovinos Santa Inês mantidos em confinamento e recebendo baixo teor de ração concentrada na dieta. Barros et al. (2005) obtiveram GPMD de 144 g/dia para cordeiros $F_{1}$ Dorper x Santa Inês, alimentados com dieta concentrada em nível de 1,5\%PV.

Para conversão alimentar verifica-se diferença significativa $(\mathrm{p}<0,05)$ dos animais não suplementados, em relação aos que recebiam $1,5 \% \mathrm{PV}$ contudo não foi observada diferença significativa $(p>0,05)$ destes para os animais suplementados com 1,0\%PV. Não houve efeito do ambiente $(p>0,05)$ sobre a CA. Estes resultados são melhores que os encontrados por Barros et al. (1994) para cordeiros Santa Inês mantidos em confinamento recebendo capim-elefante à vontade mais suplementação concentrada, que registraram CA de 6,1. 


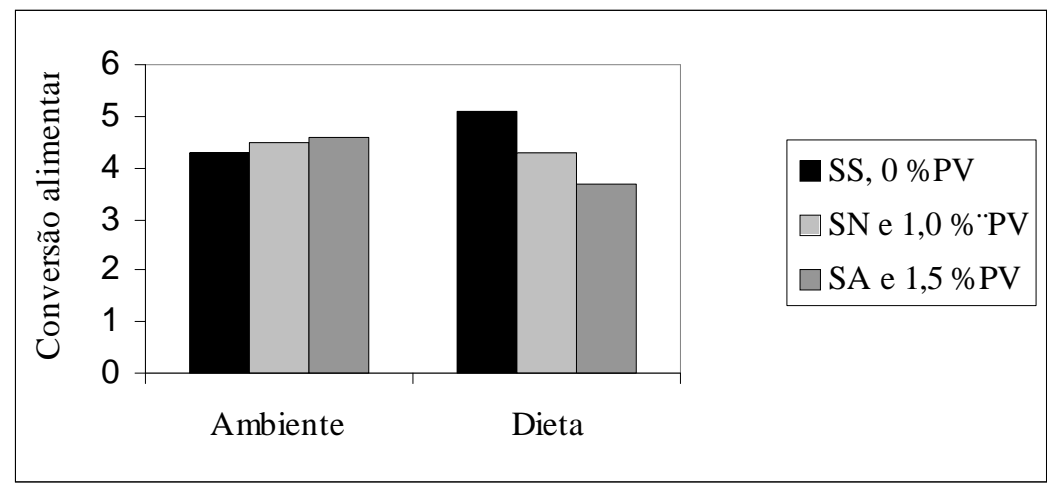

FIGURA 3 - Médias da conversão alimentar (CA) em função do ambiente (sem sombra, sombra natural e sombra artificial) e da dieta $(0,1,0$ e $1,5 \% \mathrm{PV})$.

Estes resultados são piores do que os obtidos por Furusho-Garcia et al. (2004) que encontraram CA de 3,5 para cordeiros Santa Inês entre $15-25 \mathrm{~kg}$ e recebendo suplementação concentrada para um ganho de $300 \mathrm{~g} /$ dia. Barros et al. (2003) encontraram CA de 4,9 para cordeiros Santa Inês recebendo suplementação concentrada à base de feno de leucena.

\section{CONCLUSÕES}

O provimento de sombras natural ou artificial auxilia os ovinos a manterem a homeotermia com menor esforço do aparelho termorregulatório.

O desempenho de cordeiros da raça Santa Inês, em pastagem nativa enriquecida com capim buffel, pode ser melhorado quando suplementado $1,5 \%$ do peso vivo, com concentrado.

\section{REFERÊNCIAS BIBLIOGRÁFICAS}

ABI SAAB, S.; SLEIMAN, F. T. Physiological responses to stress of filial crosses compared to local Awassi sheep. Small Ruminant Research, [S.1.], v. 16, p. 55-59, 1995.

AGRICULTURALAND FOOD RESEARCH COUNCIL. The nutrition of sheep. Walhingford: CAB Internacional, 1993. $118 \mathrm{p}$.

ARAÚJO FILHO, J. A.; LEITE, E. R.; SILVA, N. L. Contribution of woody species to the diet composition of goat and sheep in caatinga vegetation. Pasture Tropicalis, [S.1.], v. 20, p. 41-45, 1998.
ARRUDA, F. A. V.; SILVA, F. L. R.; KAWAS, J. R.; SHELTON, M. Efeito da exposição à sombra e ao sol e do nível de nutrição sobre o desempenho e fisiologia de ovinos da raça Santa Inês. In: REUNIÃO ANUAL DA SOCIEDADE BRASILEIRA DE ZOOTECNIA, 1998, Botucatu. Anais... Botucatu: Unesp, 1998.

BACCARI JÚNIOR, F. Métodos e técnicas de avaliação da adaptabilidade dos animais às condições tropicais. In: SIMPÓSIO INTERNACIONAL DE BIOCLIMATOLOGIA ANIMAL NOS TRÓPICOS: PEQUENOS E GRANDES RUMINANTES, 1., 1990, Sobral, CE. Anais... Sobral: Embrapa-CNPC, 1990. p. 9-17.

BARBOSA, C. M.; BUENO, M. S.; CUNHA, E. A. Consumo voluntário e ganho de peso de borregas das raças santa Inês, Suffolk e ile de france, em pastejo rotacionado sobre panicum maximum jacq. Cvs aruana ou Tanzânia. Boletim de Indústria Animal, Nova Odessa, v. 60, n. 1, p. 55-62, 2003.

BARROS, N. N.; FIGUEIREDO, E. A. P.; FERNANDES, F. D.; BARBIERI, M. E. Ganho de peso e conversão alimentar de cordeiros cruzas no estado do Ceará. Pesquisa Agropecuária Brasileira, Brasília, v. 29, n. 8, p. 1313-1317, 1994.

BARROS, N. M.; VASCONCELOS, V. R.; ARAÚJO, M. R. A.; MARTINS, E. C. Influência do grupo genético e da alimentação sobre o desempenho de cordeiros em confinamento. Pesquisa Agropecuária Brasileira, Brasília, v. 38, n. 9, p. 1111-1116, 2003. 
BARROS, N. N.; VASCONCELOS, V. R.; WANDER, A. E.; ARAÙJO, M. R. A. Eficiência bioeconômica de cordeiros F1 Dorper x Santa Inês para produção de carne. Pesquisa Agropecuária Brasileira, Brasília, v. 40, n. 8, p. 825-831, 2005.

BIANCA, W.; KUNZ, P. Physiological reactions of hree breedes of goats to cold, heat and hight altitude. Livestock Production Science, Amsterdam, v. 5, n. 1, p. 57-69, 1978.

BRASIL. Secretaria Nacional de Irrigação. Departamento Nacional de Meteorologia. Normas climatológicas: 19611990. Brasília, DF: Embrapa-SPI, 1992. 84 p.

BUFFINGTON, D. E.; COLLAZO-AROCHO, A.; CANTON, G. H. Black globe-humidity index (BGHI) as confort equation for dairy cows. Transactions of the ASAE, Michigan, v. 24, n. 3, p. 711-714, 1981.

CESAR, M. F.; SOUZA, B. B.; SOUZA, W. H. Avaliação de parâmetros fisiológicos de ovinos Dorper, Santa inês e seus mestiços perante condições climáticas do trópico semi-árido nordestino. Ciência e Agrotecnologia, Lavras, v. 28, n. 3, p. 614-620, maio/jun. 2004.

CEZÁRIO, A. S.; SILVA, H. G. O.; SANTOS, C. C. Efeito do sombreamento sobre o comportamento fisiológico de ovinos da raça Santa Inês. In: REUNIÃO ANUAL DA SOCIEDADE BRASILEIRA DE ZOOTECNIA, 41., 2004, Campo Grande, MS. Anais... Campo Grande: SBZ, 2004. p. 1-3.

FURUSHO-GARCIA, I. F.; PÉREZ, J. R. O.; BONAGURIO, S.; ASSIS, R. M.; PEDREIRA, B. C.; SOUZA, X. R. Desempenho de cordeiros Santa Inês puros e cruzas Santa Inês com Texel, Ile de France e Bergamácia. Revista Brasileira de Zootecnia, Viçosa, v. 33, n. 6, p. 1591-1603, 2004.

HAFEZ, E. S. E. Adaptacion de los animales domésticos. Barcelona: Labor, 1973. 563 p.

INSTITUTO BRASILEIRO DE GEOGRAFIA E ESTATÍSTICA. Censo agropecuário 2001. Rio de Janeiro, 2001.
LU, C. D. Effects of heat stress on goat production. Small Ruminant Research, [S.1.], v. 2, p. 151- 162, 1989.

MENDES, M. A.; LEÃO, M. I.; SILVA, J. F. C. Efeito da temperatura ambiente e do teor de energia da ração sobre os consumos de alimentos e de água e algumas variáveis fisiológicas de ovinos. Revista da Sociedade Brasileira Zootecnia, Viçosa, v. 5, n. 2, p. 173-187, 1976.

NEIVA, J. N. M.; TEIXEIRA, M.; TURCO, S. H. N. Efeito do estresse climático sobre os parâmetros produtivos e fisiológicos de ovinos Santa Inês mantidos em confinamento na região litorânea do nordeste do Brasil. Revista Brasileira de Zootecnia, Viçosa, v. 33, n. 3, p. 668-678, 2004.

PÁDUA, J. T.; SILVA, R. G. Efeito do estresse térmico sobre o desempenho e características fisiológicas em borregos ideal. In: REUNIÃO ANUAL DA SOCIEDADE BRASILEIRA DE ZOOTECNIA, 33., 1996, Fortaleza. Anais... Fortaleza: Sociedade Brasileira de Zootecnia, 1996. v. 1, p. 657-659.

SAS INSTITUTE. Statistical Analysis System: user's guide: statistics. Version 6.11. Washington, 1999. 842 p.

SILANIKOVE, N. Effects of heat stress on the welfare of extensively managed domestic ruminants. Livistuok Producion Science, [S.1.], v. 67, p. 1-18, 2000.

SOUZA, B. B.; ANDRADE, I. S.; SILVA, A. M. A. Efeito da suplementação concentrada e do sombreamento natural e artificial no desempenho de cordeiros Santa Inês em pastejo na região semi-árida da Paraíba. In: REUNIÃO ANUAL DA SOCIEDADE BRASILEIRA DE ZOOTECNIA, 42., 2005, Goiânia, GO. Anais... Goiânia: SBZ, 2005. CD-ROM.

TARGA, L. A.; BALLARIN, A. W.; MARTA FILHO, J. Ventilação natural em instalações para animais. In: CONGRESSO BRASILEIRO DE ENGENHARIA AGRÍCOLA, 23., 1993, Ilhéus, BA. Anais... Ilhéus: SBEACEPLAC, 1993. v. 1, p. 98-106.

TERRILL, C. E.; SLEE, J. Breed differences in adaptation of sheep. In: MAIJALA, K. Genetic resources of pigs, sheep and goat. Amsterdam: Elsevier, 1991. p. 195-233. 